\title{
ANALYSIS OF THE MOTOR ACTIVITIES OF PROFESSIONAL POLISH SOCCER PLAYERS
}

\author{
MARCIN ANDRZEJEWSKI ${ }^{1}$, BEATA PLUTA ${ }^{1}$, MAREK KONEFAŁ2, PAWE ${ }^{2}$ CHMURA ${ }^{3}$, JAN CHMURA² \\ IPoznań University of Physical Education, Faculty of Tourism and Recreation, Chair of Recreation \\ 2 University School of Physical Education in Wrocław, Faculty of Sports Science, \\ Department of Athlete's Motor Skills \\ ${ }^{3}$ University School of Physical Education in Wrocław, Faculty of Physical Education, Chair of Team Games
} Mailing address: Marcin Andrzejewski, Poznań University of Physical Education, Chair of Recreation, 27/39 Królowej
Jadwigi Street, 61-871 Poznań, tel.: +48 604595720, fax: +48 618 517384, e-mail: andrzejewski@awf.poznan.pl

\begin{abstract}
Introduction. The aims of the present study were to determine the activity profiles of a large sample of Polish Premier League soccer players during elite-standard soccer matches depending on their position on the pitch and the intensity range of physical activity. Material and methods. The study sample comprised 1,178 players in 5 outfield positions: external defenders (ED, $\mathrm{n}=$ 289), central defenders ( $C D, n=307)$, central midfield players ( $C M, n=327)$, external midfield players $(E M, n=152)$, and forwards (F, $\mathrm{n}=103)$. Altogether, 81 Polish League games held during four domestic seasons (2010-2011, 2011-2012, 2012-2013, and 2013-2014) were used in the analysis. A semi-automatic computerised player tracking system (Amisco Pro ${ }^{\circ}$, version 1.0.2, Nice, France) was applied to create the match activity profiles of the teams. Results. The results of statistical analysis revealed that the average total distance covered by all the players $(\mathrm{n}=1,178)$ was $11,313 \pm 852 \mathrm{~m}$. With respect to the players' position on the pitch, the central midfielders travelled the longest average distance $(11,894 \pm 765 \mathrm{~m})$ during the game. The longest distance was covered in the V1 intensity range (62\%), followed by V2 (15\%), V3 (10\%), V4 (8\%), V5 (3\%), and V6 (2\%). Conclusions. The objective of this study was to verify the differences among playing positions and to quantify the demands placed on elite Polish soccer players in each individual position during match play. While analysing elite-level match play in terms of the overall distance covered in different categories of intensity, we found a number of statistically significant differences between different playing positions. The data presented in this study can be regarded as norms for elite soccer players, serve for present and future comparison, and represent the scientific basis for developing position-specific conditioning/training protocols in soccer.
\end{abstract}

Key words: soccer, match analysis, distance covered, positional role

\section{Introduction}

Soccer is one of the most complex sports in which the attainment of good results depends on multiple, strictly interconnected factors $[1,2]$. It is a very dynamic game featuring an ever growing number of direct one-on-one plays, requiring perfect motor, technical, tactical, and mental preparation from the players [3].

The acyclical character of the movements, high variability of in-game situations, and pace of the game require great amounts of aerobic and anaerobic energy from various energy sources [4, 5]. During a soccer game, short-lasting exercises performed with maximal intensity (sprinting, jumping, sliding) and high intensity (counter-attacking) involving primarily anaerobic energy metabolic processes are intertwined with exercises of moderate intensity (accelerations) and low intensity (walking, jogging) involving mainly aerobic energy processes. Maximal-intensity exercise in soccer is interrupted with rest breaks lasting from a few to more than 10 seconds $[6,7]$.

Playing time, exercise intensity, and the percentage of time spent performing particular actions are all clear indicators that match performance predominantly involves aerobic energy processes, as confirmed by Bangsbo [4]. Low-intensity exercise and rest breaks during match play are necessary for muscle relaxation, body recovery, and lactate utilisation, as well as for paying the oxygen debt which develops during the performance of high- and maximal-intensity exercise. The high level of physical fitness and training accelerates all the aforementioned reactions and physiological-biochemical processes.

The players' higher than average levels of endurance, strength, and speed capabilities allow them to fully exploit their soccer skills during a game. The knowledge of the structure of players' movements during a match is the first step towards rationally designing fitness training, which determines the further development of soccer skills $[8,9]$.

The characteristics of match performance indicate the significant role of the motor preparation of modern soccer players before the playing season. They directly affect players' exploitation of their technical and tactical skills during a match.

In sport, tracking the course of the competition is highly significant. This pertains in particular to soccer, in which the match outcome directly affects many members of a team. Soccer players' movements are often monitored with the aid of match motion analysis systems that provide valuable data which can be used in training theory and practice. Motion analysis is the basis for planning the distribution of training loads [10, 11, 12, 13, 14].

Currently, two match analysis systems are used in soccer: one is based on the GPS, and the other one uses semi-automatic cameras for tracking players' actions on the field. These are Amisco Pro, which was first applied in the research by Liberman 
et al. [15] and Mohr et al. [16], developed by Di Salvo et al. [17, 18], and Pro Zone, applied by Rampinini et al. [19] and Grant and Lovell [20]. The application of motion analysis systems allows researchers to obtain structured quantitative and qualitative sets of data on the kinematic and tactical parameters of soccer players on the field.

The aims of the present study were to determine the activity profiles of a large sample of Polish Premier League soccer players during elite-standard soccer matches depending on the playing position and the intensity range of physical activity.

\section{Material and methods}

The study sample comprised 1,178 players in 5 outfield positions: external defenders (ED, $\mathrm{n}=289$ ), central defenders $(C D, n=307)$, central midfield players $(C M, n=327)$, external midfield players (EM, $\mathrm{n}=152)$, and forwards $(\mathrm{F}, \mathrm{n}=103)$. The profiles of different playing positions were based on the activities performed on the pitch and the primary area in which these activities were carried out, as in Di Salvo et al. [18].

Altogether, 81 Polish League games which were held during four domestic seasons (2010-2011, 2011-2012, 2012-2013, and 2013-2014) were used in the analysis.

The analysis involved the motor activities of the players participating in the entire match, excluding the goalkeepers. The study was conducted in compliance with the Declaration of Helsinki and was approved by the local ethics committee (No. 339/02).

The semi-automatic computerised player tracking system Amisco Pro (version 1.0.2, Nice, France) was used to create the match activity profiles of the teams. This multiple-camera system passively tracks the movements of every player over the entire course of the match using a sampling rate of $25 \mathrm{~Hz}$ [21]. An operator simultaneously encodes each player's action. Physical performances were determined automatically based on the raw data file by computerised analysis of player movements and actions using match-analysis software (Athletic, Mode Amisco Pro, Nice, France). The functioning, accuracy, and reliability of the Amisco Pro system in measuring player movements and coding game-specific events in elite soccer competitions have been described in more detail elsewhere [18, 22, 23, 24].

The match analysis system also made it possible to determine the distance covered by the players during the match in six different motor activity intensity ranges: $0 \leq \mathrm{Vl}<11 \mathrm{~km} \mathrm{~h}^{-1}$ (standing, walking), $11 \leq \mathrm{V} 2<14 \mathrm{~km} \mathrm{~h}^{-1}$ (jogging), $14 \leq \mathrm{V} 3<$ $17 \mathrm{~km} \mathrm{~h}^{-1}$ (running), $17 \leq \mathrm{V} 4<21 \mathrm{~km} \mathrm{~h}^{-1}$ (fast running), $21 \leq \mathrm{V} 5<$ $24 \mathrm{~km} \mathrm{~h}^{-1}$ (high-speed running), and V6 $\geq 24 \mathrm{~km} \mathrm{~h}^{-1}$ (sprinting).

The normality of the distribution of the variables was assessed using the Lilliefors test $(p<0.01)$. Arithmetic means, standard deviations, and non-outlier ranges were calculated for all variables.

The figures present the descriptive statistics calculated for the movements performed by the players and distances covered by them with regard to the playing position and intensity range. Multi-factor analysis of variance (ANOVA) was used to compare the players' motor activities and mean distances covered by them in regard to the playing position (CD, ED, CM, EM, and F) and range of movement intensity/velocity (V1, V2, V3, V4, V5, and V6). Initially, a complete model was used to evaluate all interactions. Statistically non-significant interactions were then ignored, and the significant ones were analysed using the ANOVA. Statistically significant differences between mean values were measured with the Tukey HSD test. The level of statistical significance was set at $\mathrm{p}<0.05$. All statistical calculations were made using the STATISTICA 10.0 software package.

\section{Results}

The empirical data concerning the distances covered by the players of different tactical formations in particular activity intensity ranges are presented in table 1 .

Table 1. Mean distances covered by the Polish Premier League soccer players $(\mathrm{n}=1,178)$ according to the playing position and intensity/velocity range (V1 to V6). The players were classified into five positional groups: external defenders (ED, $n=289)$, central defenders $(C D, n=307)$, central midfield players (CM, $\mathrm{n}=327$ ), external midfield players (EM, $\mathrm{n}=152)$, and forwards $(\mathrm{F}, \mathrm{n}=103)$. All values of distances covered are provided in metres

\begin{tabular}{|c|c|c|c|c|c|c|c|c|}
\hline \multirow[b]{2}{*}{ Positions } & \multicolumn{8}{|c|}{ Distances covered in different velocity ranges } \\
\hline & & $\begin{array}{c}0 \leq \mathrm{V} 1<11 \\
\mathrm{~km} \mathrm{~h}^{-1}\end{array}$ & $\begin{array}{c}11 \leq \mathrm{V} 2<14 \\
\mathrm{~km} \cdot \mathrm{h}^{-1}\end{array}$ & $\begin{array}{c}14 \leq \mathrm{V} 3<17 \\
\mathrm{~km} \cdot \mathrm{h}^{-1}\end{array}$ & $\begin{array}{c}17 \leq \mathrm{V} 4<21 \\
\mathrm{~km} \mathrm{~h} \mathrm{~h}^{-1}\end{array}$ & $\begin{array}{c}21 \leq \mathrm{V} 5<24 \\
\mathrm{~km} \cdot \mathrm{h}^{-1}\end{array}$ & $\begin{array}{l}V 6 \geq 24 \\
\mathrm{~km} \cdot \mathrm{h}^{-1}\end{array}$ & $\begin{array}{c}\text { Total } \\
\text { IND PER }\end{array}$ \\
\hline ED & Distances [m] & $\begin{array}{l}7001 \\
(286)\end{array}$ & $\begin{array}{l}1677 \\
(239)\end{array}$ & $\begin{array}{l}1152 \\
(204)\end{array}$ & $\begin{array}{c}934 \\
(200)\end{array}$ & $\begin{array}{c}344 \\
(103)\end{array}$ & $\begin{array}{c}324 \\
(125)\end{array}$ & $\begin{array}{c}11432 \\
(558)\end{array}$ \\
\hline$C D$ & Distances [m] & $\begin{array}{l}7104 \\
(264)\end{array}$ & $\begin{array}{l}1512 \\
(250)\end{array}$ & $\begin{array}{c}894 \\
(187)\end{array}$ & $\begin{array}{c}647 \\
(155)\end{array}$ & $\begin{array}{l}217 \\
(73)\end{array}$ & $\begin{array}{l}174 \\
(77)\end{array}$ & $\begin{array}{c}10503 \\
(528)\end{array}$ \\
\hline $\mathrm{CM}$ & Distances [m] & $\begin{array}{l}6983 \\
(315)\end{array}$ & $\begin{array}{l}1973 \\
(337)\end{array}$ & $\begin{array}{l}1400 \\
(315)\end{array}$ & $\begin{array}{l}1032 \\
(266)\end{array}$ & $\begin{array}{c}317 \\
(108)\end{array}$ & $\begin{array}{l}189 \\
(90)\end{array}$ & $\begin{array}{c}11894 \\
(765)\end{array}$ \\
\hline EM & Distances [m] & $\begin{array}{l}7004 \\
(302)\end{array}$ & $\begin{array}{l}1740 \\
(327)\end{array}$ & $\begin{array}{l}1231 \\
(294)\end{array}$ & $\begin{array}{l}1022 \\
(242)\end{array}$ & $\begin{array}{c}383 \\
(105)\end{array}$ & $\begin{array}{c}370 \\
(133)\end{array}$ & $\begin{array}{c}11751 \\
(686)\end{array}$ \\
\hline $\mathbf{F}$ & Distances $[\mathrm{m}]$ & $\begin{array}{l}7053 \\
(272)\end{array}$ & $\begin{array}{l}1424 \\
(296)\end{array}$ & $\begin{array}{c}967 \\
(225)\end{array}$ & $\begin{array}{c}819 \\
(181)\end{array}$ & $\begin{array}{l}326 \\
(97)\end{array}$ & $\begin{array}{c}308 \\
(126)\end{array}$ & $\begin{array}{c}10897 \\
(724)\end{array}$ \\
\hline & $\begin{array}{l}\text { Total IND } \\
\text { PER }\end{array}$ & $\begin{array}{l}7028 \\
(294)\end{array}$ & $\begin{array}{l}1690 \\
(353)\end{array}$ & $\begin{array}{l}1148 \\
(317)\end{array}$ & $\begin{array}{c}888 \\
(265)\end{array}$ & $\begin{array}{c}307 \\
(114)\end{array}$ & $\begin{array}{c}252 \\
(132)\end{array}$ & \\
\hline
\end{tabular}


Table 2 presents the statistically significant differences between the ANOVA and post-hoc Tukey HSD test results. Figures 1-2 show the characteristics of the total distance covered by the Polish Premier League soccer players $(n=1,178)$, depending on the playing position and activity intensity range.

Statistically significant differences were found for the playing position $(\mathrm{F}=457.7 ; \mathrm{p} \leq 0.001)$ and intensity range $(\mathrm{F}=$ 192,157.0; $\mathrm{p} \leq$ 0.001). Statistically significant interactions were observed between the intensity range and playing position $(\mathrm{F}=$ 114.6; $\mathrm{p} \leq$ 0.001).

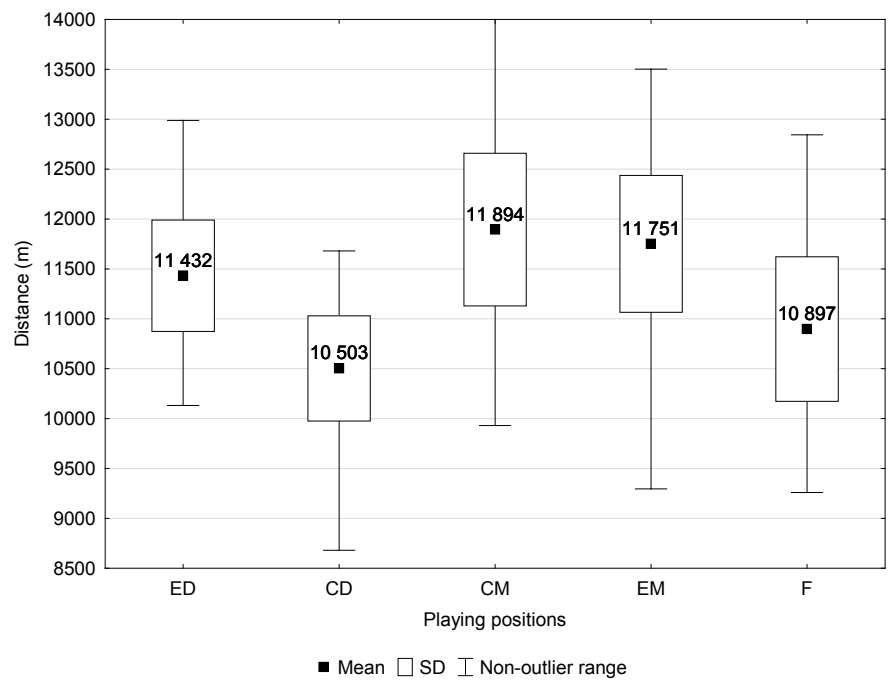

Figure 1. Characteristics of the distance covered (metres) by the players $(\mathrm{n}=1,178)$ classified into five positional groups: external defenders ( $E D, n=289$ ), central defenders ( $C D, n=307)$, central midfield players $(\mathrm{CM}, \mathrm{n}=327)$, external midfield players $(\mathrm{EM}, \mathrm{n}=152)$ and forwards $(\mathrm{F}, \mathrm{n}=103)$



Figure 2. Characteristics of the distance covered (metres) by the players $(\mathrm{n}=1,178)$ in six different intensity/velocity ranges: $0 \leq \mathrm{Vl}<11 \mathrm{~km} \mathrm{~h}^{-1}$ (standing, walking), $11 \leq \mathrm{V} 2<14 \mathrm{~km} \mathrm{~h}^{-1}$ (jogging), $14 \leq \mathrm{V} 3<17 \mathrm{~km} \mathrm{~h}^{-1}$ (running), $17 \leq \mathrm{V} 4<21 \mathrm{~km} \mathrm{~h}^{-1}$ (fast running), $21 \leq \mathrm{V} 5<24 \mathrm{~km} \mathrm{~h}^{-1}$ (highspeed running), and $\mathrm{V} 6 \geq 24 \mathrm{~km} \mathrm{~h}^{-1}$ (sprinting)
The statistical analysis of the total distance covered by the players in match play in relation to their position on the field revealed that the longest distance was covered by central midfielders $(11,894 \pm 765 \mathrm{~m})$ and external midfielders $(11,751 \pm 686 \mathrm{~m})$, though the differences between the players in these two positions were statistically non-significant. However, these two groups of players covered significantly greater distances than external defenders $(11,432 \pm 558 \mathrm{~m})$, whereas external defenders covered significantly greater distances than forwards $(10,897 \pm 724 \mathrm{~m})$, and forwards covered significantly greater distances than central defenders $(10,503 \pm 528 \mathrm{~m})$ (fig. 1).

The analysis of the distance covered by the players in the six ranges of activity intensity revealed some statistically significant differences. The longest distance was covered with the intensity of V1 (standing, walking) - 7,028 $\pm 294 \mathrm{~m}$, followed by V2 (jogging) - 1,690 $\pm 353 \mathrm{~m}$, V3 (running) - 1,148 $\pm 317 \mathrm{~m}$, V4 (fast running) $-888 \pm 265 \mathrm{~m}$, V5 (high-speed running) $-307 \pm 114 \mathrm{~m}$, and V6 (sprinting) - $252 \pm 132 \mathrm{~m}$ (fig. 2).

The interaction between the playing position and activity intensity range revealed the following correlations. In V1 (standing, walking), there was a statistically significant difference in the distance covered between the CD $(7,104 \pm 264 \mathrm{~m})$ and the EM $(7,004 \pm 302 \mathrm{~m}), \mathrm{ED}(7,001 \pm 286 \mathrm{~m})$, and CM $(6,983 \pm 315 \mathrm{~m})$. In V2 (jogging), the CM $(1,973 \pm 337 \mathrm{~m})$ covered a significantly longer distance than the EM $(1,740 \pm 327 \mathrm{~m})$, ED $(1,677 \pm 239 \mathrm{~m})$, CD $(1469 \pm 250 \mathrm{~m})$, and F $(1,424 \pm 296 \mathrm{~m})$. Moreover, the EM and ED covered a longer distance in this intensity range than the CD and F. A similar profile of changes was noted in the analysis of the interaction between the players' position and the V3 intensity range (running). The CM $(1,400 \pm 315 \mathrm{~m})$ covered a longer distance than EM $(1,231 \pm 294 \mathrm{~m}), \operatorname{ED}(1,152 \pm 204 \mathrm{~m})$, F $(967 \pm 225 \mathrm{~m})$, and CD $(894 \pm 187 \mathrm{~m})$. Again, the EM and ED covered a longer distance in this intensity range than the $\mathrm{CD}$ and $\mathrm{F}$. In the $\mathrm{V} 4$ range (fast running), statistically significant differences were found between the CM (1,032 $\pm 266 \mathrm{~m})$, ED $(934 \pm 200 \mathrm{~m}), \mathrm{F}(819 \pm 181 \mathrm{~m})$, and CD $(647 \pm 155 \mathrm{~m})$. Statistically significant differences were also revealed between the EM $(1,022 \pm 242 \mathrm{~m}), \mathrm{F}$ and CD.

The EM $(383 \pm 105 \mathrm{~m})$, ED $(344 \pm 103 \mathrm{~m})$, and CM $(317 \pm 108 \mathrm{~m})$ covered significantly longer distances than the CD $(217 \pm 73 \mathrm{~m})$ at V5 (high speed). In the last range, i.e. V6 (sprinting), a statistically significant difference in the distance covered was found between the EM $(370 \pm 133 \mathrm{~m})$, ED $(324 \pm 125 \mathrm{~m})$, and $\mathrm{F}(308 \pm 126 \mathrm{~m})$ and the CM $(189 \pm 90 \mathrm{~m})$ and CD $(174 \pm 77 \mathrm{~m})$.

Table 2. ANOVA and Tukey test results with respect to playing position (ED, CD, CM, EM, and F) and intensity/velocity range (V1, V2, V3, V4, $\mathrm{V} 5$, and $\mathrm{V} 6)^{*}$

\begin{tabular}{|c|c|}
\hline Factor & Statistically significant differences $(p<0.05)$ \\
\hline $\begin{array}{c}\text { Playing } \\
\text { positions: }\end{array}$ & $\mathrm{CM}, \mathrm{EM}>\mathrm{ED}>\mathrm{F}>\mathrm{CD}$ \\
\hline Velocity ranges: & $\mathrm{V} 1>\mathrm{V} 2>\mathrm{V} 3>\mathrm{V} 4>\mathrm{V} 5>\mathrm{V} 6$ \\
\hline $\begin{array}{c}\text { Playing } \\
\text { positions } X \\
\text { Velocity ranges: }\end{array}$ & 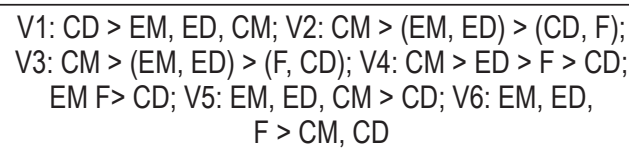 \\
\hline
\end{tabular}

*ANOVA = analysis of variance. 


\section{Discussion}

\section{Overall analysis}

The purpose of this study was to quantify the activity of players playing in different positions and to analyse the differences between the effort profiles in different intensity ranges. The study included 1,178 Polish Premier League soccer players playing in four domestic seasons (2010-2011, 2011-2012, 20122013, and 2013-2014). The data were obtained from 81 matches.

The results of the present study show that the mean total distance covered by the Polish elite soccer players, regardless of their playing position, amounted to $11,313 \pm 852 \mathrm{~m}$. This is similar to the results obtained by other authors $[9,22,25,26$, 27,28 ]. It should be noted, however, that these authors studied players' match performances using various forms of motion analysis. Authors who applied the Amisco Pro system in their research include Di Salvo et al. [18] and Andrzejewski et al. [29]. The total distance covered by the players in their studies was

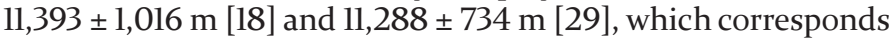
to the results in the present study (tab. 1).

The mean total distance covered by a player during a match can be divided into that covered by walking (38.9\%), jogging (29.5\%), running between 13 and $16 \mathrm{~km} \mathrm{~h}^{-1}$ (13.3\%), running between 16 and $19 \mathrm{~km} \mathrm{~h}^{-1}(8.4 \%)$, and sprinting (9.8\%) [30].

Motion analysis results indicate that the majority of matchplay activities are performed with low intensity (jogging, walking, and moving backwards) or submaximal intensity (fast running). Only a small part of the distance is covered by soccer players with maximal intensity (sprinting). However, the acyclical and intermittent nature of soccer also involves short-lasting exercises performed with maximal intensity [16].

The current state of knowledge has been confirmed by the results of the present study. The distance covered in the six ranges of intensity clearly showed that the longest distance was covered in the $\mathrm{Vl}$ range (standing, walking), that is 7,028 $\pm 294 \mathrm{~m}$ (fig. 2), which accounts for about $62 \%$ of the total distance covered in match play. In all subsequent ranges of intensity, the players ran shorter distances (tab. 1). This is similar to the results obtained by Andrzejewski et al. [29] in their study of 31 soccer players taking part in 4 matches of the UEFA Cup in the 2008/2009 season.

The data recorded in the study prove the importance of the high level of aerobic endurance for the motor preparation of soccer players. It allows players to increase the intensity of their activities during matches and maintain it for much longer. A player with a high level of aerobic endurance is more tolerant and resistant to incremental fatigue and can also recover faster. A shorter recovery time after performing exercise of high intensity allows the player to engage earlier and more effectively in consecutive actions of maximal intensity [31].

Soccer is an intermittent sport involving brief, intense bursts of exercise that seem to be the key to successful performance [30]. In the present study, the players examined covered a mean distance of $252 \pm 132 \mathrm{~m}$ in the V6 intensity range, that is sprinting at $24 \mathrm{~km} \mathrm{~h}^{-1}$, which constituted merely $2.2 \%$ of the total distance covered. Such authors as Di Salvo et al. [18], Delall et al. [8], Lago et al. [32], and Andrzejewski et al. [33] also recorded similar results using the Amisco Pro motion analysis system.

\section{Impact of playing position}

An analysis of data available in the literature reveals differences in the length of the distance covered in match play in relation to players' positions on the pitch [30, 34]. These dif- ferences may depend on the team's playing style [35] or tactics $[18,36]$, the level of the opposing team [4], as well as on the players' physical condition [11, 37]. There are differences in terms of the total distance covered and particular distances run with high intensity [38]. Depending on the team's tactical approach, including the players' positions on the pitch, the energy for performing activities can be generated from aerobic and anaerobic processes in appropriate proportions during match play [39]. The player's position on the pitch determines their activity profile, the length of the distance covered, and the intensity of their activity. It has been suggested that the ability to play with high intensity is the most important measure of fitness in elite players [40], which is crucial for the development of training programmes $[18,29]$.

The present study also aimed to determine in which playing positions the soccer players covered the longest distance during match play. The motion analysis of 81 matches of the Polish Premier League showed that the longest total distance was covered by the central midfielders $(11,894 \pm 765 \mathrm{~m})$ and external midfielders $(11,751 \pm 686 \mathrm{~m})$. A significantly shorter distance was covered by the external defenders $(11,432 \pm 558 \mathrm{~m})$, forwards $(10,897 \pm 724 \mathrm{~m})$, and central defenders $(10,503 \pm 528 \mathrm{~m})$ (fig. 1). These values, which are higher than those for other positions, have to do with the dual role of midfielders, who participate in both offensive and defensive sequences of the play [30].

These results have been confirmed by Di Salvo et al. [18] who found that the longest total distance was covered by central midfielders. Also central and external midfielders of the Spanish Premiera Division and English Premier League ran the longest distances in the 2006-2007 season [9]. The total distances covered by players in these positions were significantly longer than those covered by players in other positions on the pitch.

In the current study, the central defenders were found to spend significantly more time standing and walking and cover a longer distance in this category of the activity than players in any other position. However, CD spent the smallest amount of time and covered the shortest distance in all other intensity ranges. This is consistent with the results obtained by Rampinini et al. [41] showing that central defenders covered the lowest distance at high intensity.

Midfield players (CM and EM), on the other hand, were found to spend the smallest amount of time standing and walking, but they covered the greatest distances in running and fast running. External midfield players (EM) were the ones who spent the highest percentage of time and covered the greatest distance in sprinting. However, the time spent and distance covered by EM players did not differ significantly from those recorded for the ED and F.

Similar conclusions were reached in the research by $\mathrm{Di}$ Salvo et al. [40], where the Amisco Pro system was used, which showed that external midfielders ran the longest distance with a speed of over $23 \mathrm{~km} \mathrm{~h}^{-1}$.

\section{Conclusions}

The objective of this study was to verify differences among playing positions and quantify the demands placed on elite Polish soccer players in each of the individual positions during the match. While analysing the elite-level match play in terms of the overall distance covered at different intensities, we found that there were a number of statistically significant differences between the different playing positions.

A thorough analysis of players' match performance makes it possible to select training loads which are appropriate for the 
development of soccer-specific motor skills in terms of character, volume, and intensity. This analysis is the basis for individualising general physical training and the training of particular motor skills. The knowledge of the profile and characteristics of match exercise, that is match loads, is necessary for football training programming at any stage. The lack of such data gathered during matches may, in effect, lead to overload or underload of players' bodies.

In summary, the results of the present study, which used a high-tech motion analysis system, can help increase the quality of soccer training through greater individualisation of training loads, ensure more optimal selection of tactical tasks for individual players, and contribute to the development of soccer worldwide.

\section{Literature}

1. Stølen T., Chamari K., Castagna C. (2005). Physiology of soccer: An update. Sports Medicine 35, 501-536.

2. Bangsbo J., Krustrup P. (2008). Physical demands and training of top-class soccer players. In T. Reilly, F. Korkusuz (eds), Science and football VI (pp. 318-330). New York, USA: Routledge.

3. Reilly T. (2007). The science of training - soccer: A scientific approach to developing strength, speed, and endurance. New York, USA: Routledge.

4. Bangsbo J. (1994). The physiology of soccer: With special reference to intense intermittent exercise. Acta Physiologica Scandinavica 151 (Suppl. 619), 1-155.

5. Reilly T. (2003). Motion analysis and physiological demands. In T. Reilly, A.M. Williams (eds), Science and soccer (pp. 9-72). London, UK: E \& FN Spon.

6. Spencer M., Bishop D., Dawson B., Goodman C. (2005). Physiological and metabolic responses of repeated-sprint activities. Sports Medicine 35, 1025-1044.

7. Andrzejewski M., Chmura J., Pluta B., Konarski J. (2015). Sprinting activities and distance covered by top level Europa League Soccer Players. International Journal of Sports Science \& Coaching 10(1), 39-50.

8. Dellal A., Wong D.P., Moalla W., Chamari K. (2010). Physical and technical activity of soccer players in the French First League - with special reference to their playing position. International Journal of Sports Medicine 11, 278-290.

9. Dellal A., Chamari K., Wong D.P., Ahmaidi S., Keller D., Barros R. et al. (2011). Comparison of physical and technical performance in European soccer match-play: FA Premier League and La Liga. European Journal of Sports Sciences 11, 51-59.

10. Wisløff U., Helgerud J., Hoff J. (1998). Strength and endurance of elite soccer players. Medicine Science and Sports Exercise 30, 462-467.

11. Reilly T., Bangsbo J., Franks A. (2000). Anthropometric and physiological predispositions for elite soccer. Journal of Sports Sciences 18, 669-683.

12. Rienzi E., Drust B., Reilly T., Carter J.E.L., Martin A. (2000). Investigation of anthropometric and work-rate profiles of elite South American international players. Journal of Sports Medicine and Physical Fitness 40, 162-169.

13. Helgerud J., Engen L.C., Wisløff U., Hoff J. (2001). Aerobic endurance training improves soccer performance. Medicine Science and Sports Exercise 33, 1925-1931.

14. Krustrup P., Mohr M., Ellingsgaard H., Bangsbo J. (2005). Physical demands during an elite female soccer game: Im- portance of training status. Medicine and Science in Sports and Exercise 37, 1242-1248.

15. Liebermann D.G., Katz L., Hughes M.D., Bartlett R.M., McClements J., Franks I.M. (2002). Advances in the application of information technology to sport performance. Journal of Sports Science 20, 755-769.

16. Mohr M., Krustrup P., Bangsbo J. (2003). Match performance of high-standard soccer players with special reference to development of fatigue. Journal of Sports Science 21, 519528.

17. Di Salvo V., Collins A., Mc Neill B., Cardinale M. (2006). Validation of ProZone. A new video-based performance analysis system. International Journal of Performance Analysis in Sports 26, 108-119.

18. Di Salvo V., Baron R., Tschan H., Calderon Montero F.J., Bachl N., Pigozzi F. (2007). Performance characteristics according to playing position in elite soccer. International Journal of Sports Medicine 28, 222-227.

19. Rampinini E., Bishop D., Marcora S.M., Ferrari Bravo D., Sassi R., Impellizzeri F.M. (2007). Validity of simple field tests as indicators of match-related physical performance in top-level professional soccer players. International Journal of Sports Medicine 28, 228-235.

20. Grant A., Lovell R. (2009). The use of individualized speed and intensity thresholds for determining the distance run at high-intensity in professional soccer. Journal of Sports Science 27, 893-898.

21. Carling C., Williams A.M., Reilly T. (2005). The handbook of soccer match analysis. Abingdon, UK: Routledge.

22. Carling C., Bloomfield J., Nelsen L., Reilly T. (2008). The role of motion analysis in elite soccer: Contemporary performance measurement techniques and work-rate data. Sports Medicine 38, 839-862.

23. Randers M.B., Mujika I., Hewitt A., Santisteban J., Bischoff R., Solano R. et al. (2010). Application of four different football match analysis systems: A comparative study. Journal of Sports Sciences 28, 171-182.

24. Zubillaga A., Gorospe G., Hernadez-Mendo A., BlancoVillanesor A. (2008). Comparative analysis of the highintensity activity of soccer players in top-level competition. In T. Reilly, F. Korkusuz (eds), Science and football VI (pp. 182-186). Abingdon, UK: Routledge.

25. Barros R., Milton S., Misuta R.P., Menezes P.J., Figueroa F.A., Moura S.A. et al. (2007). Analysis of the distances covered by first division Brazilian soccer players obtained with an automatic tracking method. Journal of Sports Science and Medicine 6, 233-242.

26. Di Salvo V., Gregson W., Atkinson G., Tordoff P., Drust B. (2009). Analysis of high intensity activity in premier league soccer. International Journal of Sports Medicine 30, 205212.

27. Carling C., Dupont G. (2011). Are declines in physical performance associated with a reduction in skill-related performance during professional soccer match-play? Journal of Sports Sciences 29, 63-71.

28. Vigne G., Dellal A., Gaudino C., Chamari K., Rogowski I., Alloatti G. et al. (2013). Physical outcome in a successful Italian Serie A soccer team over three consecutive seasons. Journal of Strength and Conditioning Research 27, 1400-1406.

29. Andrzejewski M., Chmura J., Pluta B., Kasprzak A. (2012). Analysis of motor activities of professional soccer players. Journal of Strength and Conditioning Research 26, 14811488. 
30. Vigne G., Gaudino C., Rogowski I., Alloatti G., Hautier C. (2010). Activity profile in elite Italian Soccer Team. International Journal of Sports Medicine 31, 304-310.

31. Andrzejewski M., Chmura J., Dybek T., Pluta B. (2012). Sport exercise capacity of soccer players at different levels of performance. Biology of Sport 29, 185-191.

32. Lago C., Casais L., Dominguez E., Sampaio J. (2010). The effects of situational variables on distance covered at various speeds in elite soccer. European Journal of Sport Science 10, 103-109.

33. Andrzejewski M., Chmura J., Pluta B., Strzelczyk R., Kasprzak A. (2013). Analysis of sprinting activities of professional soccer players. Journal of Strength and Conditioning Research 27, 2134-2140.

34. Drust B., Reilly T., Cable N.T. (2002). Metabolic and physiological responses to a laboratory based soccer-specific intermittent protocol on a non-motorised treadmill. In W. Spinks, T. Reilly, A. Murphy (eds), Science and football IV (pp. 217-225). Sydney-London: Routledge.

35. Shephard R. (1999). Biology and medicine of soccer: An update. Journal of Sports Sciences 17, 757-786.
36. Al-Hazzaa H., Almuzaini K.S., Al-Refaee S.A., Sulaiman M.A., Dafterdar M.Y., Al-Ghamedi A. et al. (2001). Aerobic and anaerobic power characteristics of Saudi elite soccer players. Journal of Sports Medicine and Physical Fitness 41, 54-61.

37. Di Salvo V. (2001). Training of elite soccer players according to their positional roles. Doctoral thesis, Universidade Tecnica de Lisboa, Portugal.

38. O'Donoghue P. (2002). Time-motion analysis of work-rate in English FA Premier League Soccer. International Journal of Performance Analysis in Sports 2, 36-43.

39. Reilly T. (1997). Energetics of high-intensity exercise (soccer) with particular reference to fatigue. Journal of Sports Sciences 15, 257-263.

40. Di Salvo V., Baron V., Gonzalo-Haro R., Gormasz A., Pigozzi C., Bachl F. (2010). Sprinting analysis of elite soccer players during European Champions League and UEFA Cup matches. Journal of Sports Sciences 28, 1489-1494.

41. Rampinini E., Sassi A., Sassi R., Impellizzeri F.M. (2004). Variables influencing fatigue in soccer performance. International Congress on Sport Rehabilitation and Traumatology "The rehabilitation of sports muscular and tendon injuries”, 24-25 April 2004. Milan, Italy.

Submitted: August 24, 2016

Accepted: November 22, 2016 